\title{
Güçlü Yönler Öz-yeterlik Ölçeğinin Türkçe Versiyonunun Psikometrik Özellikleri ${ }^{1}$
}

\author{
DOI: 10.26466/opus.587269
}

\begin{abstract}
$*$

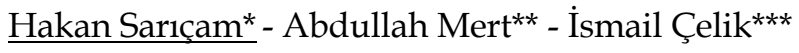

* Doç. Dr, Kütahya Dumlupınar Üniversitesi, Eğitim Fakültesi, Kütahya / Türkiye

E-Posta: hakansaricam@gmail.com ORCID: $\quad$ 0000-0002-8723-1199

** Dr. Öğr. Üyesi, Uşak Üniversitesi, Eğitim Fakültesi, Uşak/ Türkiye

E-Posta: abdullahmert@gmail.com ORCID: 0000-0003-0653-2297

*** Dr. Öğr. Üyesi, A ̆grı İbrahim Çeçen Üniversitesi, Eğitim Fakültesi, Ağr1/ Türkiye

E-Posta: icelik@agri.edu.tr ORCID: 0000-0002-6612-9224
\end{abstract}

\section{Öz}

Bu çalışmada, Güçlü Yönler Öz-yeterlik Ölçeğinin (GYÖYÖ) Türk katılımcılarda geçerlik ve güvenirliğini test etmek ve psikometrik özelliklerini incelemek amaçlanmıştır. Araştırma kapsamına yaşları 18 ile 39 arasında değişen üç farklı çalışma grubunda yer alan toplam $416(252+154+110)$ katılımò alınmıştır. Açımlayıcı faktör analizi sonuçlarına göre SMKBÖ'nün Türkçe formunun orijinalindeki gibi tek boyuta sahip olduğu ve bu tek boyutlu yapının ölçtüğ̈̈̈̈zellikle ilgili toplam varyansın \%64'ünü açıkladığı görülmüştür. Doğrulayıcı faktör analizi sonucu ölçeğin uyum iyiliği değerleri $\chi^{2} / s d=1.94$ RMSEA $=.054, A G F I=95, C F I=95, G F I=96$, IFI=96, RFI=.96 ve SRMR=.046 olarak hesaplanmıştır. Ayrıca madde faktör yükleri 64 ile .76 arasında sıralanmaktadır. Benzer ölçek (ölçüt) geçerliği çalışmasında, GYÖYÖ ile Psikolojik Sağlamlığı Değerlendirme Ölçeği ve Kısa Azim Ölçeği arasında sırasılyla $r=.58, .59$ pozitif ilişkiler tespit edilmiştir. Cronbach alfa iç tutarlık katsayısı $\alpha=.94$ olarak bulunmuştur. Düzeltilmiş madde toplam korelasyon katsayıları 67 ile .82 arasında değişmektedir. Tüm bu sonuçlar, Güçlü Yönler Öz-yeterlik Ölçeğinin Türkiye'deki üniversite öğrencilerinde ve öğretmenlerinde kullantlabilecek geçerli ve güvenilir bir ölçme aracı olduğunu göstermiştir.

Anahtar Kelimeler: Güçlü yönler, Yetenek, Bilgi, Beceri, Öz-yeterlik, Ölçek uyarlama

\footnotetext{
${ }^{1}$ Bu çalışmanın bir bölümü 9-11 Mart tarihlerinde Mardin'de gerçekleştirilen 1.Uluslararası IKSAD Sosyal Bilimler Kongresinde sözlü bildiri olarak sunulmuştur
} 


\title{
The Psychometric Properties of the Turkish Version of Strengths Self Efficacy Scale
}

\begin{abstract}
In this study, it is aimed to test the reliability and validity of Strengths Self Efficacy (SSES) Scale in Turkish people and to examine its psychometric properties. Three study groups were conducted among a total of $416(252+154+110)$ Turkish participants aged from 18 to 39. According to explanatory factor analysis results, it was found that the Turkish form of the SSES had one-dimension just like the original version and the unidimensional scale explained $64 \%$ of variance related to the attribute it measured. In confirmatory factor analysis, fit index values were found as $\chi^{2} / d f=1.94$ RMSEA $=.054$, AGFI=95, $C F I=95, G F I=96, I F I=96, R F I=.96$, and $S R M R=.046$. Factor loadings ranged from .64 to .76 . In the concurrent validity, the SSES had significant relationships with the Resilience Appraisal Scale and the Short Grit Scale ( $r=.58, .59$, respectively). Cronbach alpha internal consistency coefficient was found as $\alpha=.94$. Corrected item-total correlations ranged from .67 to .82. Overall results demonstrated that Strengths Self Efficacy Scale can be used for university students and teachers in Turkey as a valid and reliable instrument.
\end{abstract}

Keywords: Strengths, Talent, Knowledge, Skill, Self-efficacy, Scale adaptation 


\section{Giriş}

Günümüz şartları ve hızla değişen dünyada, gerek eğitim ortamında gerekse iş hayatında bireysel farklılıkların esas alındığ 1 performans değerlendirmelerde bireylerin kendini göstermesi için güçlü yönleri ve bunlara yönelik farkındalı̆̆ı daha değerli hale gelmiştir. Pozitif psikolojiyle belirgin hale gelen güçlü yönler öznel zindelik, tutku ve motivasyonu harmanlayarak akademik başarı ve iş performansında önemli etkiye sahiptir (Biswas-Diener, 2010; Dubreuil, Forest ve Courcy, 2014). Bireyin yetenek, bilgi ve becerisini kullanarak ortaya koyduğu performans, bireyin kendine yönelik inanç ve güveninin eyleme koyulmuş halidir (Tsai, Chaichanasakul, Zhao, Flores ve Lopez, 2014).

Albert Bandura' nın Sosyal Öğrenme Kuramı'nda önemini vurguladı̆̆ 1 öz-yeterlilik (Bıkmaz, 2004; Ekici, 2009; Schunk ve Pajares, 2010; Senemoğlu, 2009), bireyin özüne ilişkin pozitif kavramlardan bir diğeridir. Bandura'ya (1977) göre öz-yeterlilik, bireyin kendine verilen görevleri veya davranışları başarılı bir şekilde yerine getireceğine dair kendi yeteneklerine olan güvenidir. Öz-yeterlilik; görevlerin yerine getirilmesindeki başarma yeteneği ve güven duygusu (Devonport ve Lane, 2006; Jinks ve Morgan, 1999; Schunk, 1991), bireyin kendisiyle ilgili beklentileri ve çabalarının sonuçlarına olan inancı (Choi, 2005; Pajares, 1996; Schunk, 1991) şeklinde tanımlanmaktadır. Schunk ve Pajares (2010) öz-yeterliğin, bireyin önceki deneyimlerinden bağımsız olarak düşünülemeyeceğini ifade etmiş ve bireylerin eyleme geçmesinin ardındaki en önemli kaynağın özyeterlilik inancı olduğunu vurgulamıştır (Açıkgöz, 2000). Öz-yeterlilik inancının bireyin deneyimleri ile şekillenip gelişebileceği ve bu kavramın başarı, motivasyon, öz düzenleme, duygulanım ve psikolojik stres gibi değişkenlerle ilişki içinde olabileceği düşünüldüğünde bu kavramın, klinik psikolojiden örgüt psikolojisine kadar birçok alanda çalışma konusu olarak kendine yer bulduğu söylenebilir (Daniels ve Larson, 2001; DiClemente, Fairhurst ve Piotrowski, 1995; Luszczynska, Mohamed ve Schwarzer, 2005; Maddux, ve Rogers, 1983; Ramos-Sánchez ve Nichols, 2007; Sakız, Ekinci ve Sarıçam, 2019; Sarıçam,ve Sakız, 2014; Stajkovic ve Luthans, 1998a; Wood ve Bandura, 1989). Öz-yeterliğin karar verme üzerindeki etkisi düşünüldügünde bu inancın birçok davranışın yordayıcısı olduğu 
söylenebilir (Bandura, 1990; Lopez ve Lent, 1992; Sakız vd., 2019; Sarıçam, 2015; Stajkovic ve Luthans, 1998b; Verroen, Gutteling ve DeVries, 2013).

Bireyin kendine ve kapasitesine olan inancı üzerine temellendirilen özyeterlilik teorisinin (Coulibaly ve Karsenti, 2013) eğitimde sinıf ortamında uygulamaya konulmasının öğrencilerin öğrenmeleri üzerinde önemli bir etkisinin olduğu söylenebilir (Devonport ve Lane, 2006; Lorsbach ve Jinks, 1999; Tiyuri, Saberi, Miri, Shahrestanaki, Bayat ve Salehiniya, 2018). 417 ortaöğretim öğrencisi ile yapılan bir çalışmada öz-yeterliğin kariyer kararı verme boyutunun öğrencilerin sosyal destek ve benlik saygısı üzerinde anlamlı düzeyde pozitif bir etkisinin olduğu görülmüştür (Mert, Duman ve Kahraman, 2019). Bireyin başarıya ulaşmada sadece performansı değil başarabileceğine olan inancı da başarısını etkilemektedir (Gangloff ve Mazilescu, 2017). Öz-yeterlilik inancı yüksek olan bireyler düşük olanlara göre bir görevi yerine getirmede daha çok çaba gösterir ve bu da performansı ve sonucu olumlu yönde etkiler (Askar ve Davenport, 2009; Bandura, 1977; Basım, Korkmazyürek ve Tokat, 2008). Fakat bireyin öz-yeterliğine olan inancı aslında onun sahip olduğu gizil güç ve kapasitesinden ziyade buna olan inancıdır yani bireyin sahip olduklarıyla sahip olduğunu düşündükleri arasında farklılıklar bulunabilir (Bolat, 2011; Luszczynska, Scholz ve Schwarzer, 2005). Mesela öz-yeterliği düşük bireyler yerine getirilmesi gereken bir görevde ya da sorumlulukta gerekli beceriye sahip olsa bile harekete geçemezken (Bandura, 1986; Ekici, 2009; Kotaman, 2008; Yıldırım ve İlhan, 2010;), öz-yeterliği yüksek olan birey daha fazla sorumluluk alarak harekete geçecek ve o görev ve sorumluluğu tamamlayacaktır (Bandura, 2002; Kiremit, 2006). Yine düşük öz-yeterlilik düzeyine sahip bireyler karşı karşıya kaldıkları problemler karşısında direnmeyip çabuk vazgeçerken yüksek öz-yeterlilik düzeyine sahip bireyler, problem çözme ve baş etme konusunda geliştirici özelliklere sahiptir (Aktamış, Kiremit ve Kubilay, 2016; Basım vd., 2008; Pajares, Johnson ve Usher, 2007). Fakat öz-yeterliğin başarıya ulaşmada tek etkili faktör olduğu söylenemez (Yılmaz, Gürçay ve Ekici, 2007). Öz-yeterliğin geliştirilebilir bir yetenek olduğu düşüldügünde performans başarısı, dolaylı yaşantılar, sözel ikna, duygusal ve fiziksel durumlar etkisi yadsınamaz. Bireyin doğrudan olumlu ve olumsuz kendi yaşantıları, model aldığı bireylerin yaşantıları, problemin üstesinden gelip gelemeyeceğine ilişkin söz ve 
nasihatler ve içinde bulunduğu duygusal, fiziksel durum öz-yeterliği etkileyen ve gelişmesine yardımcı olan kaynaklardır (Korkmaz, 2009; Kurbanoğlu, 2004). Bununla birlikte bireyin olumlu duyguları daha yoğun yaşaması, öz-yeterliği güçlendirirken olumsuz duygular öz-yeterlilik üstünde zayıflatıcı bir etkiye sahiptir (Çapa Aydın, Uzuntiryaki, Temli ve Tarkın, 2013). Bireyi başarıya götüren bir başka motivasyon kaynağ umuttur (Snyder, Shorey, Cheavens, Pulvers, Adams ve Wiklund, 2002).

Tüm bunların yanı sıra bireyin sahip olduğu yetenek, bilgi ve beceri gibi özellikler bir davranışı yerine getirmede bireyin gösterdiği üst düzey performansla ilişkilidir. Pozitif psikolojide güçlü yönler olarak belirtilen bu özellikler, öz-yeterliğin güçlendirilmesinde kendilik algısına ilişkin farkındalık ve inancın önemini vurgulamakta önemli yer tutar (Clifton ve Harter, 2003; Dubreuil, Forest ve Courcy, 2014). Zimmerman (1995), özyeterliğin fiziksel veya psikolojik özelliklerden ziyade bireyin kendine inanması konusundaki yargılarını içerdiğini, öz-yeterliğin çok boyutlu bir kavram olduğunu ve her alandaki öz-yeterlilik inancının bir diğerinden farklı olduğunu, bireyden bireye sınırlık ve farklılık içerebileceğini ve performans düzeyinin standart ölçme araçlarıyla ölçülebileceğini vurgulamıştır (Bıkmaz, 2004). Bu sebepten, öğrenci gelişimini destekleyen yaşantıların araştırılması ve bireysel yeteneklerin istendik biçimde açığa çıarılmasını hedefleyen güçlü yönlü eğitim ilkelerinin uygulamaya konulması öz-yeterlilik açısından önemli bir yere sahiptir (Lopez ve Louis, 2009).

Bireyin kendi yetenek, bilgi ve becerilerinin farkına varıp; üst düzeyde anlama ve örgütleme performansı göstermesi için ona gereken fırsatları sağlamak güçlü yönler temelli gelişim modelinin esaslarındandır (Clifton ve Anderson, 2002; Hodges ve Clifton, 2004). Güçlü yönlere ilişkin farkındalık, iş performansını arttırmak için pozitif sermaye olmasının (Hodges ve Asplund, 2010) yanı sıra umut, mutluluk, öznel iyi oluş ve yaşam doyumunun da önemli bir bileşenidir (Lane ve Chapman, 2011; LittmanOvadia ve Steger, 2010; Peterson, Ruch, Beermann, Park ve Seligman, 2007). Clifton Güçlü Yönler Bulucu Envanteri (Asplund, Lopez, Hodges ve Harter, 2007) ile Tsai vd. (2014) tarafından geliştirilen Güçlü Yönler ÖzYeterlik Ölçeği gibi güçlü yönleri belirleme ve değerlendirme araçları bu yönlerin ortaya çıkarılması, keşfedilmesi veya kullanılmasında fayda sağlayacağı aşikârdır (Lane ve Chapman, 2011). Linley, Woolston ve BiswasDiener (2009) güçlü yönler öz-yeterliliğinin bir liderlik özelliği olduğunu 
ve koçluk eğitimiyle bireylerde bu yönlerin geliştirilebileceğini vurgulamıştır. Bireylerin güçlü yönlerine odaklanma ve kendi kendilerine yeterlik inançlarını geliştirmede koçluk hizmetleri ve kariyer danışmanlığı gibi pozitif psikoloji temelli müdahalelerin katkısının büyük olacağı (BiswasDiener, 2010; Biswas-Diener, Kashdan ve Minhas, 2011; Linley vd., 2009); bunun için güçlü yönlere ilişkin öz-yeterlilik inancının saptanması geçerli ve güvenilir psikometrik ölçüm araçlarıyla gerçekleştirilebileceği düşünüldüğünde, Güçlü Yönler Öz-Yeterlik Ölçeğinin ulusal literatüre önemli katkı sağlayacağı söylenebilir. Bu çalışmanın amacı Güçlü Yönler Öz-yeterlik Ölçeğinin (GYÖYÖ) Türk katılımcılarda geçerlik ve güvenirliğini test etmek ve psikometrik özelliklerini incelemektir.

\section{Yöntem}

\section{Katılımcilar}

Araştırmanın üç farklı çalışma grubunu Ağrı, Uşak ve Kütahya illerinde bulunan öğretmenler ve üniversite öğrencilerinden oluşan toplamda 416 katılımcı oluşturmuştur. İlk grubun 117'si erkek, 135'i kadın (n=252); ikinci grubun 105'i kadın, 49'u erkek (n=154); üçüncü grubun 72'si kadın ve 38'i erkek ( $n=110$ ) olup; tüm katılımcıların yaşları 18 ile 39 arasında değişmektedir.

\section{Veri toplama araçları}

Güçlü Yönler Öz-yeterlik Ölçeği (GYÖYÖ): Orijinal versiyonu kariyer danışmanlığı alanında kullanılsın diye Tsai vd. (2014) tarafından bireylerin algıladığı becerileri değerlendirebilmek için geliştirilen GYÖYÖ'̈̈ 11 maddeden oluşan tek boyutlu bir ölçme aracıdır. Ölçek kendini değerlendirmeye yönelik 11 'li ( $0=$ Hiç güvenmem------ 5=Orta düzeyde güvenirim----10=Tamamiyla güvenirim) derecelendirmeye sahip Likert tipi bir ölçme aracıdır. Ölçekten en düşük 0 puan en yüksek 110 puan alınabilmektedir. Artan puanlar güçlü yönlere yönelik öz-yeterlik inancının arttığını göstermektedir. Ölçeğin yapı geçerliği AFA ve DFA ile incelenmiştir. İlk aşamada 275 yetişkinden elde edinilen verilere AFA yapılmış ve sonuçta tek boyutlu bir yapıl elde edilmiştir. Bu yapının Cronbach alfa iç 
tutarlık güvenirlik katsayıs1 .96 bulunmuştur. Daha sonra AFA'da ortaya çıkan yapı için 302 yetişkinden elde edinilen veriye DFA yapılmış ve yapının doğrulandığı tespit edilmiştir. Ölçeğin benlik saygısı ve yaşam doyumu ile orta düzeyde pozitif ilişkiler; sosyal istenirlik ile düşük düzeyde negatif ilişki tespit edilmiştir. Ölçeğin Cronbach alfa iç tutarlık güvenirlik katsayısı ise .95 olarak hesaplanmıştır. Ayrıca test tekrar test güvenirliği için 3 hafta arayla 36 yetişkine uygulama sonucu iki uygulama arası korelesyon sayısı yüksek çıkmıştır.

Psikolojik Sağlamlı̆̆ı Değerlendirme Ölçeği (PSDÖ): Sarıçam ve diğerleri tarafından (2012) Türkçeye uyarlanmış ölçek, bireylerin psikolojik sağlamlık düzeylerini belirlemek için kullanılmaktadır. Ölçek 5'li Likert (1= Hiç katılmıyorum-5=Tamamen katılıyorum) türde olup, 12 madde ve 3 alt boyuttan (sosyal destek, duygusal başa çıkma ve durumsal başa çıkma) oluşmaktadır. Yapı geçerliğinde üç boyutlu model için uygulanan DFA sonucu uyum indeksi değerleri: $\chi^{2}=117.28, \mathrm{sd}=47, \mathrm{RMSA}=.060, \mathrm{CFI}=.97$, $\mathrm{IFI}=.97, \mathrm{GFI}=.96, \mathrm{NFI}=.95$, SRMR .49 olarak bulunmuştur. Ölçeğin faktör yükleri 38 ile .70 arasında sıralanmaktadır. Cronbach alfa iç tutarlılık katsayıları ölçeği bütünü için .81, sosyal destek alt boyutu için .66, duygusal başa çıkma alt boyutu için.73, durumsal başa çıkma alt boyutu için .71 olarak hesaplanmıştır. Düzeltilmiş madde-toplam korelasyonları .38 ile .57 arasında sıralanmaktadır. Bu çalışmada iç tutarlılık güvenirlik katsayıları ölçeğin bütünü için $\alpha=.86$ bulunmuştur.

Kısa Azim Ölçeği (K-AÖ): Sarıçam, Çelik ve Oğuz, (2016) tarafından Türkçeye uyarlanmış ölçek, bireylerin azim, sebat ve kararlılık düzeylerini belirlemek için kullanılmaktadır. Yapı geçerliğinde, doğrulayıcı faktör analizi sonucu 8 maddelik 2 boyutlu modelin uyum indeksi değerleri $\left(\chi^{2} / \mathrm{sd}=2.06, \mathrm{p}=.00011, \mathrm{RMSEA}=.046, \mathrm{CFI}=.95, \mathrm{GFI}=.94, \mathrm{AGFI}=.93\right.$, $\mathrm{SRMR}=.047$ ) olup madde faktör yüklerinin .42 ile .77 arasında siralandığ 1 görülmüştür. Motivasyonel Kararlılık Ölçeği ve Kısa Azim Ölçeği arasında $r=.68 \mathrm{p}<.01$ önem düzeyinde pozitif ilişki bulunmuştur. Cronbach alfa iç tutarlık güvenirlik katsayıları ölçeği bütünü için .83, ilginin tutarlılığ alt boyutu için .80, gayrette 1srar alt boyutu için .71 olarak hesaplanmıştır. Test tekrar test güvenirlik katsayısı .69 olarak hesaplanmış olup 
düzeltilmiş madde toplam korelasyon katsayılarının .33 ile .65 arasında sıralandığı görülmüştür.

\section{Işslem}

Güçlü Yönler Öz-yeterlik Ölçeğinin Türk kültürüne uyarlama çalışması için 11 Aralık 2017 tarihinde ölçeği geliştiren Lisa Y. FLORES ile e-mail yoluyla iletişim kurulmuş ve ölçeğin Türkçeye uyarlanabileceğine ilişkin gerekli izin alınmıştır. Ölçeğin Türkçeye çevrilme süreci belli aşamalardan oluşmaktadır. Öncelikle ölçek maddeleri araştırmacılar tarafından Türkçeye çevrilmiş ve daha sonra Yabancı Diller Yüksekokulunda okutman tarafından Türkçe'den İngilizceye tekrar çevrilmiştir; iki form karşılaştırılmış Türkçeden İngilizceye çevrilen yeni form neredeyse orijinal forma yakın çıkmıştır. Türkçe Öğretmeni tarafından Türkçe form üzerinde varsa gerekli düzeltmeler yapılmış ve deneme Türkçe formu elde edilmiştir. Türkçe form ve orijinal İngilizce form İngiliz Dili ve Edebiyatından formasyon öğrencilerine (52 kişi) 8 gün arayla uygulanmış ve dilsel uyum değerleri incelenmiştir. İstatistiki değerlerinin uygunluğu görüldükten sonra hazırlanan Türkçe deneme formu, Kişisel Bilgi Formu ve diğer ölçme araçları bir araya getirilerek uygulama formu oluşturulmuş; bu form çoğaltılarak üniversite öğrencileri ile öğretmenlere araştırmacılar tarafından bizzat uygulanmıştır. Uygulama sırasında gerekli açılamalar yapılmış, kendilerine uygun bir şekilde yanıtlamaları için yönerge okunarak açıklanmış, isim yazmalarının zorunlu olmadığı, isteyenlere araştırma sonucu hakkında bilgi verilebileceği açıklanarak, cevaplarda içten olunmasının en doğru sonuca ulaşmayı sağlayacağı ifade edilmiştir. Uygulamalar yaklaşık olarak 9 dakika sürmüştür. Dağıtılan bu formlar toplanarak, verilerin bilgisayar ortamına aktarılması sağlanmıştır. Araştırmada psikometrik özellikler: Dilsel eşdeğerlik, yapı geçerliği, ölçüt geçerliği, test tekrar test güvenirliği, iç tutarlık güvenirlik ve madde analizi ile incelenmiştir. Yapı geçerliği için açıklayıcı faktör analizi (AFA) ve doğrulayıcı faktör analizi (DFA) yapılmıştır. AFA, en uygun faktör sayısını ve maddelerin çeşitli gizil boyutlarda olup olmayacağını belirler. DFA ise varsayılan ya da belirlenmiş bir faktör yapısının, maddelerin gözlenen kovar- 
yans yapısına uygunluğunu sınamaktadır. Geçerlik ve güvenirlik analizleri SPSS/AMOS 23 paket programıla yapılmıştır. Önem düzeyi olarak $\mathrm{p}<.01$ ölçüt alınmıştır.

\section{Bulgular}

\section{Dilsel Eşdeğerlik}

İki dildeki test puanları arasındaki ilişknin tespit edilmesi gerektiğinden (Anastasi ve Urbina, 1997, s.141) Spearman Korelasyon katsayısı kullanılmış ve bulgular Tablo 1'de gösterilmiştir. Ayrıca iki dili bilen katılımcıların her bir maddeden aldıkları Türkçe ve İngilizce puan ortalamaları arasındaki farklılık Mann Whitney $U$ testi ile analiz edilmiş ve sonuçlar Tablo 2 ' de gösterilmiştir.

Tablo 1. Ölçeğin maddelerinin Ingilizce ve Türkçe puanlarının karşılaştırılmasına ilişkin Spearman Korelasyon değerleri

\begin{tabular}{|c|c|c|c|c|c|c|}
\hline Madde no & Dil & $\mathbf{N}$ & $\bar{X}$ & ss & $\mathbf{r}$ & $p$ \\
\hline \multirow{2}{*}{ M1 } & İngilizce & 52 & 7.02 & 2.68 & \multirow{2}{*}{.95} & \multirow{2}{*}{.00} \\
\hline & Türkçe & 52 & 7.31 & 2.38 & & \\
\hline \multirow{2}{*}{ M2 } & İngilizce & 52 & 6.73 & 2.72 & \multirow{2}{*}{.84} & \multirow{2}{*}{.00} \\
\hline & Türkçe & 52 & 6.60 & 2.25 & & \\
\hline \multirow{2}{*}{ M3 } & İngilizce & 52 & 6.77 & 2.56 & \multirow{2}{*}{.82} & \multirow{2}{*}{.00} \\
\hline & Türkçe & 52 & 6.63 & 2.33 & & \\
\hline \multirow{2}{*}{ M4 } & İngilizce & 52 & 7.60 & 2.28 & \multirow{2}{*}{.77} & \multirow{2}{*}{.00} \\
\hline & Türkçe & 52 & 7.44 & 2.06 & & \\
\hline \multirow{2}{*}{ M5 } & İngilizce & 52 & 7.44 & 2.09 & \multirow{2}{*}{.86} & \multirow{2}{*}{.00} \\
\hline & Türkçe & 52 & 7.21 & 2.09 & & \\
\hline \multirow{2}{*}{ M6 } & İngilizce & 52 & 7.10 & 2.39 & \multirow{2}{*}{.74} & \multirow{2}{*}{.00} \\
\hline & Türkçe & 52 & 6.85 & 1.84 & & \\
\hline \multirow{2}{*}{ M7 } & İngilizce & 52 & 7.81 & 2.47 & \multirow{2}{*}{.83} & \multirow{2}{*}{.00} \\
\hline & Türkçe & 52 & 7.69 & 2.04 & & \\
\hline \multirow{2}{*}{ M8 } & İngilizce & 52 & 7.04 & 2.60 & \multirow{2}{*}{.81} & \multirow{2}{*}{.00} \\
\hline & Türkçe & 52 & 6.90 & 2.23 & & \\
\hline \multirow{2}{*}{ M9 } & İngilizce & 52 & 7.33 & 2.31 & \multirow{2}{*}{.70} & \multirow{2}{*}{.00} \\
\hline & Türkçe & 52 & 6.88 & 1.90 & & \\
\hline \multirow{2}{*}{ M10 } & İngilizce & 52 & 7.63 & 2.27 & \multirow{2}{*}{.78} & \multirow{2}{*}{.00} \\
\hline & Türkçe & 52 & 7.12 & 2.08 & & \\
\hline \multirow{2}{*}{ M11 } & İngilizce & 52 & 8.37 & 2.18 & \multirow{2}{*}{.96} & \multirow{2}{*}{.00} \\
\hline & Türkçe & 52 & 8.63 & 1.76 & & \\
\hline
\end{tabular}


${ }^{* *} p<.01$

Tablo 1'de görüldüğü üzere ölçeğin her bir maddesinin İngilizce ve Türkçe puanlarının karşılaştırılmasına ilişkin Spearman korelasyon değerleri $\mathrm{rs}_{\mathrm{s}}=.70$ ila .96 arasında değişmekte olup; $\mathrm{p}<.00$ önem düzeyinde arasında yüksek ilişkiyi göstermektedir.

Tablo 2. Her bir maddenin İngilizce ve Türkçe puanlarının karşılaştırılmasına ilişkin Mann Whitney U testi sonuçları

\begin{tabular}{|c|c|c|c|c|c|c|}
\hline Madde no & Dil & $\mathbf{N}$ & Sira ort. & Siralar top & $\mathbf{U}$ & p \\
\hline \multirow{2}{*}{ M1 } & İngilizce & 52 & 51.20 & 2662.50 & \multirow{2}{*}{1284.50} & \multirow{2}{*}{.65} \\
\hline & Türkçe & 52 & 53.80 & 2797.50 & & \\
\hline \multirow{2}{*}{ M2 } & İngilizce & 52 & 54.17 & 2817.00 & \multirow{2}{*}{1265.00} & \multirow{2}{*}{.56} \\
\hline & Türkçe & 52 & 50.83 & 2643.00 & & \\
\hline \multirow{2}{*}{ M3 } & İngilizce & 52 & 53.73 & 2794.00 & \multirow{2}{*}{1288.00} & \multirow{2}{*}{.67} \\
\hline & Türkçe & 52 & 51.27 & 2666.00 & & \\
\hline \multirow{2}{*}{ M4 } & İngilizce & 52 & 54.01 & 2808.50 & \multirow{2}{*}{1273.50} & \multirow{2}{*}{.60} \\
\hline & Türkçe & 52 & 50.99 & 2651.50 & & \\
\hline \multirow{2}{*}{ M5 } & İngilizce & 52 & 54.66 & 2842.50 & \multirow{2}{*}{1239.50} & \multirow{2}{*}{.46} \\
\hline & Türkçe & 52 & 50.34 & 2617.50 & & \\
\hline \multirow{2}{*}{ M6 } & İngilizce & 52 & 54.85 & 2852.00 & \multirow{2}{*}{1230.00} & \multirow{2}{*}{.42} \\
\hline & Türkçe & 52 & 50.15 & 2608.00 & & \\
\hline \multirow{2}{*}{ M7 } & İngilizce & 52 & 55.22 & 2871.50 & \multirow{2}{*}{1210.50} & \multirow{2}{*}{.35} \\
\hline & Türkçe & 52 & 49.78 & 2588.50 & & \\
\hline \multirow{2}{*}{ M8 } & İngilizce & 52 & 54.68 & 2843.50 & \multirow{2}{*}{1238.50} & \multirow{2}{*}{.45} \\
\hline & Türkçe & 52 & 50.32 & 2616.50 & & \\
\hline \multirow{2}{*}{ M9 } & İngilizce & 52 & 56.55 & 2940.50 & \multirow{2}{*}{1141.50} & \multirow{2}{*}{.16} \\
\hline & Türkçe & 52 & 48.45 & 2519.50 & & \\
\hline \multirow{2}{*}{ M10 } & İngilizce & 52 & 56.70 & 2948.50 & \multirow{2}{*}{1133.50} & \multirow{2}{*}{.15} \\
\hline & Türkçe & 52 & 48.30 & 2511.50 & & \\
\hline \multirow{2}{*}{ M11 } & İngilizce & 52 & 51.07 & 2655.50 & \multirow{2}{*}{1277.50} & \multirow{2}{*}{.61} \\
\hline & Türkçe & 52 & 53.93 & 2804.50 & & \\
\hline
\end{tabular}

${ }^{* *} p<.01$

Tablo 2 incelendiğinde her bir maddenin İngilizce ve Türkçesinden al1nan puan ortalamaları karşılaştırılmış ve $U$ değerleri $\mathrm{p}<.05$ önem düzeyinde istatistiksel olarak anlamsız çıkmıştır. Bir diğer ifadeyle İngilizce ve Türkçe formdan alınan puanlar birbirine çok yakındır. 


\section{Yapr geçerliği}

\section{Açıklayıcı faktör analizi (AFA)}

AFA için örneklem büyüklügünün 200 üstünün kabul edilebilir olduğu belirtilmiştir (Loehlin, 2004), fakat madde ve faktör sayısına göre bu say1nın değişebileceği unutulmamalıdır. AFA çalışmalarında temel bileşenler analizinden yararlanılmış olup faktör döndürme yöntemlerine başvurulmamıştır. 252 üniversite öğrencisinden elde edinilen veriler için KaiserMeyer-Olkin (KMO) örneklem uygunluk katsayıs1 .95, Bartlett küresellik testi sonucu $\chi^{2}=1967.97$ (sd=55, $\left.\mathrm{p}<.001\right)$ olarak hesaplanmıştır. Yamaç grafiğine göre özdeğeri 1'den büyük tek faktör olduğu gözlenmiş olup; AFA madde faktör yük değerlerine ilişkin bulgular ise Tablo 3'te gösterilmiştir.

Tablo 3. AFA faktör yükleri ve varyans değeri

\begin{tabular}{llll}
\hline Madde no & Yük değerleri & Madde no & Yük değerleri \\
\hline M1 & .809 & M7 & .831 \\
M2 & .781 & M8 & .784 \\
M3 & .834 & M9 & .810 \\
M4 & .819 & M10 & .722 \\
M5 & .862 & M11 & .734 \\
M6 & .800 & & \\
Varyans \% & & $\mathbf{6 3 . 9 6}$ & \\
\hline
\end{tabular}

Tablo 3'te görüldüğü üzere maddeler ölçeğin orijinalindeki gibi tek faktör altında toplanmış ve bu yapı toplam varyansın \%64'ünü açılamıştır. AFA madde faktör yükleri ise .72 ile .86 arasında sıralanmıştır. Faktör yüklerinin .40 'dan yukarı olması manidardır.

\section{Doğrulayıcı faktör analizi (DFA)}

Öğretmen adaylarından elde edinilen verilere DFA yapmadan önce varsayımların sağlanıp sağlanmadığı kontrol edilmiş; uç değerler atılmış ve normallik sağlandığı için analize devam edilmiştir. En çok olabilirlik parametre kestirim yaklaşımının tercih edildiği DFA sonucu uyum indeksi değerleri $\chi^{2} / \mathrm{sd}=1.94 \mathrm{AGFI}=95, \mathrm{CFI}=95, \mathrm{GFI}=96, \mathrm{IFI}=96, \mathrm{RFI}=.96, \mathrm{SRMR}=.046$ ve $\mathrm{RMSEA}=.054$ çıkmış, sonuçlar Şekil 1'de gösterilmiştir. 


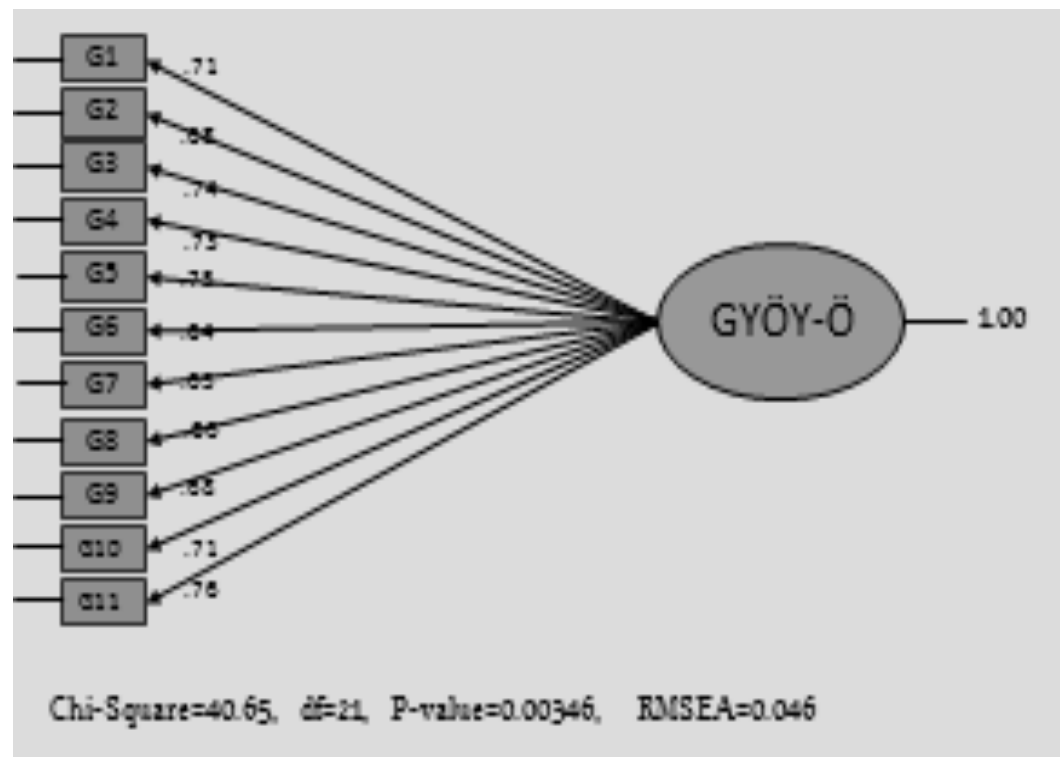

Şekil 1. DFA faktör yükleri

Şekil 1'de görüldüğü üzere DFA madde faktör yükleri .64 ila .76 arasinda siralanmaktadır.

\section{Ölçüt bă̆ıntılı geçerlik}

Benzer ölçek (ölçüt) geçerliği çalışmasında, GYÖYÖ ile PSDÖ ve K-AÖ arasındaki ilişkilere bakılmış sonuçlar Tablo 4'te gösterilmiştir.

Tablo 4. Ölçekler arası korelasyon değerleri

\begin{tabular}{|c|c|c|c|c|c|}
\hline Değişken & GYÖYÖ & PSDÖ & K-AÖ & $X$ & Ss \\
\hline GYÖYÖ & - & $.58^{* * 4}$ & $.59 *$ & 79.97 & 19.88 \\
\hline PSDÖ & & - & $.51^{* *}$ & 47.44 & 6.56 \\
\hline K-AÖ & & & - & 26.81 & 4.48 \\
\hline
\end{tabular}

"p< $p$ <01 (GYÖYÖ=Güçlii Yönler Öz-yeterlik Ölçeği, PSÖ=Psikolojik Sağlamlık Değerlendirme Ölçeği, K-AÖ=Kısa Azim Öllçeği)

Tablo 4'te görüldüğü üzere GYÖYÖ ( $\bar{X}=79.97)$ ile PSDÖ ( $\bar{X}=47.44)$ ve K-AÖ ( $\overline{\mathrm{X}}=26.81$ ) arasinda $\mathrm{p}<.01$ önem düzeyinde sirasiyla $r=.58, .59$ pozitif ilişkiler tespit edilmiştir. 


\section{Güvenirlik}

Üniversite öğrencilerinden 52 kişilik gruba 2 hafta sonra yapılan uygulama sonucu test tekrar test korelasyon katsayısı $r=.77$ olup; korelasyon katsayısının .70 ile .90 arasında olması ilişkinin çok yüksek olduğunu göstermektedir. Bir başka ifadeyle uygulamadan 2 hafta sonra geçse bile ölçek tekrar uygulandığında yakın değerler veriyordur. Ayrıca öğretmen gruptan elde edinilen verilere dayalı Cronbach alfa iç tutarlık güvenirlik katsayısı $\alpha=.94$ olarak bulunmuştur.

\section{Madde analizi}

Ölçeğe ait maddelerin birbiriyle ilişkili korelasyon değerlerin tespit etmek için madde analizleri yapılmış ve bulgular Tablo 5'te verilmiştir.

Tablo 5. Düzeltilmiş madde toplam korelasyon katsayıları

\begin{tabular}{llc}
\hline Madde no & Düzeltilmiş madde toplam korelasyon Madde silinirse Cronbach a \\
\hline M1 & .763 & .937 \\
M2 & .732 & .939 \\
M3 & .792 & .936 \\
M4 & .773 & .937 \\
M5 & .824 & .935 \\
M6 & .752 & .938 \\
M7 & .788 & .936 \\
M8 & .733 & .939 \\
M9 & .764 & .937 \\
M10 & .667 & .941 \\
M11 & .681 & .940 \\
\hline
\end{tabular}

Tablo 5'te görüldüğü üzere, düzeltilmiş madde toplam korelasyon katsayıları .67 ile .82 arasında siralanmaktadır. Bu katsayıların .30'dan bazı kaynaklarda .32'den yukarı olması gerekmektedir. Dolayısıyla ölçek maddelerine ait değerler bu kriteri sağlamaktadır. Ayrıca maddelerin ayırıcılık indekslerini tespit etmek için alt\%27 ve üst \%27 gruplara ait t değerlerin incelenmiş sonuçlar Tablo $6^{\prime}$ da verilmiştir. 
Tablo 6. Maddelerin ayırt edicilik indeksleri

\begin{tabular}{|c|c|c|c|c|}
\hline No & Ort & Ss & t (Alt-üst \%27) & $\mathbf{p}$ \\
\hline \multirow{2}{*}{ M1 } & 5.42 & 1.47 & \multirow{2}{*}{20.15} & \multirow{2}{*}{.00} \\
\hline & 9.60 & .73 & & \\
\hline \multirow{2}{*}{ M2 } & 5.06 & 1.59 & \multirow{2}{*}{19.75} & \multirow{2}{*}{.00} \\
\hline & 9.47 & .76 & & \\
\hline \multirow{2}{*}{ M3 } & 5.67 & 1.66 & \multirow{2}{*}{16.17} & \multirow{2}{*}{.00} \\
\hline & 9.40 & .76 & & \\
\hline \multirow{2}{*}{ M4 } & 6.11 & 1.41 & \multirow{2}{*}{18.08} & \multirow{2}{*}{.00} \\
\hline & 9.61 & .61 & & \\
\hline \multirow{2}{*}{ M5 } & 6.08 & 1.25 & \multirow{2}{*}{20.31} & \multirow{2}{*}{.00} \\
\hline & 9.60 & .59 & & \\
\hline \multirow{2}{*}{ M6 } & 5.72 & 1.47 & \multirow{2}{*}{17.45} & \multirow{2}{*}{.00} \\
\hline & 9.43 & .82 & & \\
\hline \multirow{2}{*}{ M7 } & 6.40 & 1.95 & \multirow{2}{*}{13.31} & \multirow{2}{*}{.00} \\
\hline & 9.76 & .43 & & \\
\hline \multirow{2}{*}{ M8 } & 5.76 & 1.73 & \multirow{2}{*}{15.51} & \multirow{2}{*}{.00} \\
\hline & 9.45 & .74 & & \\
\hline \multirow{2}{*}{ M9 } & 6.10 & 1.46 & \multirow{2}{*}{17.30} & \multirow{2}{*}{.00} \\
\hline & 9.58 & .64 & & \\
\hline \multirow{2}{*}{ M10 } & 6.12 & 1.54 & \multirow{2}{*}{17.16} & \multirow{2}{*}{.00} \\
\hline & 9.69 & .59 & & \\
\hline \multirow{2}{*}{ M11 } & 7.14 & 1.80 & \multirow{2}{*}{12.36} & \multirow{2}{*}{.00} \\
\hline & 9.97 & .18 & & \\
\hline
\end{tabular}

$" p<.01$

Tablo 6'da görüldügü üzere madde (alt-üst \%27) ayırt edicilik indeksi puanları $\mathrm{p}<.01$ önem düzeyinde istatistiksel olarak anlamlı bir şekilde farklılaşmaktadır.

\section{Tartışma}

Güçlü Yönler Öz-Yeterlilik Ölçeğinin Türk kültüründeki psikometrik özelliklerini incelemeyi amaçlayan bu çalışmada öncelikle dilsel uyum çalışmaları yapılmıştır. Her iki dili iyi kullanan katılımcıların ölçeğin hem Türkçe hem de İngilizce formunda her bir maddeden aldığı puanlar neredeyse eşittir. Üstelik maddelerin Türkçe ve İngilizce ifadeleri arasındaki korelasyon değerleri çok yüksektir. Bu bulgulardan hareketle ölçeğin dilsel eşdeğerliği sağlanmıştır denilebilir. Daha sonra yapı geçerliği için iki 
farklı veri setine AFA ve DFA yapılmıştır. AFA sonucunda KMO değeri 0.80-0.90 arası olduğu için bu veri grubu için örneklem sayısının faktör analizine uygun olduğu söylenebilir. Ayrıca Bartlett küresellik testinin manidarlık değeri .05 alfa değerinden küçük olduğu için yokluk hipotezi ret edilir. Bu durumda korelasyon matrisi birim matris olmayıp faktör analizi için uygundur (Sarıçam ve Adam Karduz, 2018). Bununla birlikte ölçeğin AFA sonucunda maddelerin faktör yük değerleri .60 ve üstü olması maddelerin faktörle ilişkisinin yüksek (Kline, 1994:6) olduğunu göstermektedir. Buna paralel olarak madde faktör yüklerinin birçok madde için .80 ve üstü olması ilişkinin çok yüksek olduğunu (Guadagnoli ve Velicer, 1988) göstermektedir. Ayrıca açıklanan varyansın \%64 olması basit yapılarda kabul edilebilir bir orandır. Kline (1994) kompleks yapılarda her bir faktörün toplam varyansın $\% 15$ 'i toplamda $\% 40$ 'tan fazlasını; basit yapılarda toplam varyansın 2/3'ünü açıklaması gerektiğini belirtmiştir. AFA'dan elde edinilen yapının denk olan bir başka çalışma grubunda doğrulanıp doğrulanmadığını tespit etmek için yapılan DFA sonucu uyum indeksi değerlerinden $\chi^{2} / \mathrm{sd}$, AGFI, CFI, GFI, IFI, RFI, SRMR ve RMSEA değerleri alanyazında belirtilen ölçütlere $\left(\chi^{2} / \mathrm{sd} \leq 2\right.$, AGFI > .95, CFI $>.95$, GFI $>.95$, IFI $>.95$, RFI $>.95$, SRMR $\leq .05$, RMSEA $\leq .05)$ göre mükemmel uyum (Brown, 2006; Harrington, 2009; Kline, 2005) göstermektedir. Ölçüt bağıntılı geçerlik çalışmasında GYÖYÖ'nin PSDÖ ve K-AÖ ile $\mathrm{p}<.01$ önem düzeyinde .50 üstü ilişki katsayılarına sahip olması alanyazında orta düzeyde ilişki (Alper, 2006) olarak adlandırıldığından ölçüt geçerliliğinin kısmen sağlandığı söylenebilir.

Ölçeğin güvenirlik analizlerinde Cronbach alfa iç tutarlık güvenirlik katsayısının .70'ten büyük (Celik, Akin ve Saricam, 2014;Nunnally, 1974; Saricam ve Canatan, 2015) olması iç tutarlık güvenirliğinin psikolojik testlerde kabul edilebilir olduğunu göstermektedir. Ayrıca test tekrar test güvenirliği için iki uygulama arası korelasyon değerinin .70 'ten büyük olması korelasyon değeri olarak yüksek düzeyde ilişkiyi (Alper, 2006) göstermekte olup ölçeğin tutarlılığının iyi olduğunun da göstergesidir.

GYÖYÖ'nün ayırt ediciliği hesaplanırken madde-toplam korelasyonları hesaplanmıştır. Madde toplam korelasyonun 0.40 ve üstü olduğu durumlarda madde ayırt edici olarak kabul edilir ve olduğu gibi teste alınabilir (Çetin, Bars ve Bars, 2015). Ölçekte yer alan tüm maddelerin maddetoplam korelasyon değerlerinin .65 'ten yukarı olması herbir maddenin iyi 
düzeyde ayırt edici olduğu anlamına gelmektedir.Ayrıca \%27'lik alt-üst gruplar arası Mann Whitney testi sonuçları tüm maddeler için anlamlı bir farklılık olduğunu göstermektedir. Bir başka ifadeyle madde ayırıcılık gücü indeks değerlerine göre her bir madde, güçlü yönler öz yeterliliğine sahip olanlar ile olmayanları ayırabilmektedir. Ölçeğin başka kültürlerde uyarlamasına rastlanılmamış olup, Türkçe ve orijinal formunun yakın geçerlik ve güvenirlik değerlerine sahip olduğunu söylemek pek de yanlış olmayacaktır.

\section{Sonuç}

Bu sonuçlara dayanarak ölçeğin dilsel eşdeğerliliğe sahip, Türk popülasyonundaki bireylerin güçlü yönlerine dair öz-yeterlik düzeylerini değerlendirmede geçerli ve güvenilir bir ölçme aracı olduğu söylenebilir. Ölçeğin özellikle kariyer danışmanlığı için önemli bir boşluğu dolduracağı düşünülmektedir. Ölçeğin uyarlama çalışmasında bir uyarlama çalışması için ne tür varsayım ya da gereklilik varsa yapılmaya çalışılmıştır. Fakat ölçeğin ölçüm ve değerlendirme gücünü arttırmaya ilişkin;

- Dil kapsam geçerlik çalışması yapılabilir,

- Paralel formlar ya da iki yarı test güvenirliği hesaplanabilir,

- Ergen ve lise örneklemi gibi farklı çalışma gruplarıyla çalışma genişletilebilir. 


\title{
EXTENDED ABSTRACT
}

\section{The Psychometric Properties of the Turkish Ver- sion of Strengths Self Efficacy Scale}

\author{
Hakan Sarıçam - Abdullah Mert - İsmail Çelik
}

Dumlupınar University, Uşak University, İbrahim Çeçen University

In the social context, cognitive and emotional reactions would be motived by the beliefs a person holds about his/her efficacy, which generates the notion of perceived self-efficacy. Self-efficacy in general is defined by Bandura as one's thoughts about his/her ability to achieve. According to Bandura, self-efficacy is a key component of the self-system, which consists of an individual's attitudes, abilities, and cognitive resources.

Strength is the ability to provide consistent, near-perfect performance in a specific task using a set of individual talents, knowledges, and skills. Strengths self-efficacy is the level of one's confidence in her/his ability to practice and apply her/his strengths. Strengths self-efficacy is based on hope, which serves "an activating force that enables people, even when faced with the most overwhelming obstacles, hardships, and difficulties to envision a promising future and to set and pursue goals".

Awareness about strengths self-efficacy increases one's confidence in mastering new domains and enhances one's accomplishments and feelings of personal wellbeing. Strengths self-efficacy may encourage one to set higher expectations for future performances. Therefore, it is important for career counseling. In this study, it is aimed to test the reliability and validity of Strengths Self Efficacy Scale (SSES) in Turkish people and to examine its psychometric properties.

\section{Methodology}

\section{Participants}

Three study groups were conducted among a total of $416(252+154+110)$ Turkish participants aged from 18 to 39 . These participants were teachers 
and university students and they lived in Agri, Kutahya, and Usak in Turkey.

\section{Instruments}

Personal Information Form, the Resilience Appraisal Scale, and Short Grit Scale were used for data gathering.

\section{Procedure}

With Lisa Y. FLORES, one of the developers for the adaptation study of the Strengths Self Efficacy Scale was contacted via e-mail and permission for the adaptation to Turkish obtained (11/12/2017). The translation process of the scale into Turkish consists of specific stages. Firstly, the scale was translated into Turkish by researchers, and these Turkish forms were applied to 52 English Language and Literature university students. Thus, the integrity between the two forms is examined. The Turkish forms were then prepared, copied and issued with necessary explanations to the participant students. The completed scales were then gathered, and the data transferred to a computer for analysis. The psychometric properties of the scale was examined with test methods; linguistic equivalence, descriptive factor analysis, confirmatory factor analysis, criterion-related validity, internal consistency, and test-retest. For concurrent validity, the Resilience Appraisal Scale and Short Grit Scale were used. $\mathrm{p}<.01$ is based as the level of significance.

\section{Findings}

In the cultural and linguistic equivalence study, each items correlation coefficients between the English form scores and the Turkish form scores of 52 participants were found to be $r_{s}=.70$ to .96 . According to explanatory factor analysis results, Kaiser-Meyer-Olkin (KMO) measure of sampling adequacy was .95 and there was a significant result on Bartlett's test of Sphericity $\chi^{2}=1967.97(\mathrm{df}=55, \mathrm{p}<.001)$. Moreover, it was found that the Turkish form of the SSES had one-dimension just like the original version 
and the unidimensional scale explained $64 \%$ of variance related to the attribute it measured. In confirmatory factor analysis, fit index values were found as $\chi^{2} / \mathrm{df}=1.94$ RMSEA $=.054$, AGFI=95, CFI=95, GFI=96, IFI=96, $\mathrm{RFI}=.96$, and $\mathrm{SRMR}=.046$. Factor loadings ranged from .64 to .76 . In the concurrent validity, the SSES had significant relationships with the Resilience Appraisal Scale and the Short Grit Scale ( $r=.58, .59$, respectively). Cronbach alpha internal consistency coefficient was found as $\alpha=.94$. After the scale was applied to 52 university students from the study group in Kütahya/Turkey at an interval of 14 days, the correlation coefficient between the two applications was found to be $r=.77$. Corrected item-total correlations ranged from .67 to .82 . According to t-test results concerning the significance of the difference between the upper and lower $27 \%$ of the total mean scores, there is a significant difference in favor of the upper group.

\section{Discussion}

For AFA, factor loads are higher than the value 40 which is perfect in the literature. And for path analysis, it can be said that the scale complies very well as a one-dimension and has a perfect fit value. Because the outcome of DFA values are the indicators of perfect compliance such as $\chi^{2} / \mathrm{sd} \leq 2$, AGFI $>.95$, CFI $>.95$, GFI $>.95$, IFI $>.95$, RFI $>.95$, SRMR $\leq .05$, RMSEA $\leq$ .05 . When we look at the results of reliability studies of the SSES, the correlation coefficients which were obtained by Cronbach alpha integrity, item total correlation, and test-retest methods are at an acceptable level. With Cronbach alpha internal consistency reliability coefficient higher than .70 and corrected items total correlation values higher than .40.

\section{Conclusion}

Overall results demonstrated that Strengths Self Efficacy Scale can be used for university students and teachers in Turkey as a valid and reliable instrument.

\section{Kaynakça / References}

Açıkgöz, K. (2000). Etkili öğrenme ve öğretme. İzmir: Kan Yılmaz Matbaası. 
Aktamış, H., Kiremit, H. Ö. ve Kubilay, M. (2016). Öğrencilerin öz-yeterlik inançlarının fen başarılarına ve demografik özelliklerine göre incelenmesi. Adnan Menderes Üniversitesi Ĕ̆itim Fakültesi Eğitim Bilimleri Dergisi, 7(2), 1-10.

Alper, R. (2006). Spor bilimlerinde uygulamalı istatistik. Ankara: Nobel Akademik.

Anastasi, A. ve Urbina, S.(1997). Psychological testing (7th ed.). NJ: Prentice Hall.

Askar, P. ve Davenport, D. (2009). An investigation of factors related to selfefficacy for java programming among engineering students. The Turkish Online Journal of Educational Technology, 8(1). Retrieved From Http://Files.Eric.Ed.Gov/Fulltext/ED 503900.Pdf

Asplund, J., Lopez, S. J., Hodges, T. ve Harter, J. (2007). The Clifton StrengthsFinder 2.0 technical report: Development and validation. Princeton: Gallup Press.

Aşkar, P. ve Umay, A. (2001). İlköğretim matematik öğretmenliği öğrencilerinin bilgisayarla ilgili öz yeterlik algısı. Hacettepe Üniversitesi Ĕ̆itim Fakültesi Dergisi, 21, 1-8.

Bahadır, F. ve Tuncer, M. (2017). Öğretmen adaylarının bilimsel araştırma özyeterlikleri ve öğretmenlik mesleğine yönelik tutumları açısından değerlendirilmesi. Electronic Turkish Studies, 12(17). DOI: 10.7827/TurkishStudies.11938

Bandura, A. (1977a). Self-efficacy: toward a unifying theory of behavioral change. Psychological Review, 84, 191-215.

Bandura, A. (1977b). Social learning theory. Englewood Cliffs, NJ: PrenticeHall.

Bandura, A. (1990). Perceived self-efficacy in the exercise of control over ards infection. Evaluation And Program Planning, 13, 9-17.

Bandura, A. (1994). Self-Efficacy. In V. S. Ramachaudran (Eds.), Encyclopedia of Human Behavior. NY: Academic Press.

Bandura, A. (1995). Self-efficacy in changing societies. Cambridge University Press.

Bandura, A. (1997). Self-efficacy: The exercise of control. NY: W. H. Freeman.

Bandura, A. (2006). Guide to the construction of self-efficacy scales. In (F. Pajares and T. Urdan Eds.), Self-efficacy beliefs of adolescents (p. 307-337). Greenwich, CT: Information Age. 
Basım, H. N., Korkmazyürek, H. ve Tokat, A. O. (2008). Çalışanların öz yeterlilik algılamasının yenilikçilik ve risk alma üzerine etkisi: kamu sektöründe bir araştırma. Selçuk Üniversitesi Sosyal Bilimler Enstitüsü Dergisi, 19(2), 121-130.

Bıkmaz, F. H. (2004). Öz-yeterlik inançları. (Y. Kuzgun ve D. Deryakulu Ed.), Eğitimde bireysel farklllıklar içinde (s.289-308). Ankara: Nobel Yayın Dağıtım.

Biswas-Diener, R. (2010). Practicing positive psychology coaching: Assessment, activities, and strategies for success. Hoboken, NJ: John Wiley. DOI:10.1002/9781118269633

Biswas-Diener, R., Kashdan, T. B. ve Minhas, G. (2011). A dynamic approach to psychological strength development and intervention. The Journal of Positive Psychology, 6, 106-118. DOI:10.1080/17439760.2010.545429

Bolat, O. İ. (2011). Öz yeterlilik ve tükenmişlik ilişkisi: Lider-üye etkileşiminin aracılık etkisi. Ege Akademik Bakış Dergisi, 11(2), 255-266.

Brown, T. A. (2006). Confirmatory factor analysis for applied research. New York: The Guilford Press.

Celik, I., Akin, A. ve Saricam, H. (2014). A scale adaptation study related to the examination of adolescents' levels of educational stress. Üniversitepark Bülten, 3(1-2), 44-55. DOI: 10.12973/unibulletin.312.4

Choi, N. (2005). Self-efficacy and self-concept as predictors of college students' academic performance. Psychology in the Schools, 42(2), 197-205. DOI:10.1002/pits.20048

Clifton, D. O. ve Anderson, E. (2002). Strengthsquest: Discover and develop your strengths in cademics, career, on beyond. New York: Gallup Press.

Clifton, D. O. ve Harter, J. K. (2003). Strengths investment. In( K. S. Cameron, J. E. Dutton, and R. E. Quinn Eds.), Positive organizational scholarship (p. 111-121).San Francisco: Berrett-Koehler.

Coulibaly, M. ve Karsenti, T. (2013). Étude du sentiment d'auto-efficacité des enseignants du secondaire au niger à l'égard de l'ordinateur. Mcgill Journal of Education/Revue Des Sciences De L'éducation De Mcgill, 48(2), 383-401.

Çapa Aydın, Y. Uzuntiryaki, E., Temli, Y. ve Tarkın, A. (2013). Öz Yeterlik Kaynakları Ölçeği'nin türkçeye uyarlanması. İlköğretim Online, 12 (3), 749-758. 
Çetin, B., Bars, M. ve Bars, E. (2015). Matematik umutsuzluk ölçeğinin güvenirlik ve geçerlik çalışması. Elektronik Sosyal Bilimler Dergisi, 14(53), 163-172.

Daniels, J. A. ve Larson, L. M. (2001). The impact of performance feedback on counseling self-efficacy and counselor anxiety. Counselor Education and Supervision, 41, 120-130. DOI:10.1002/j.1556-6978.2001.tb01276.x

Devonport, T. J. ve Lane, A. M. (2006). Relationships between self-efficacy, coping and student retention. Social Behavior \& Personality: An International Journal, 34, 127-138. DOI:10.2224/sbp.2006.34.2.127

DiClemente, C. C., Fairhurst, S. K. ve Piotrowski, N. A. (1995). Self-efficacy and addictive behaviours. In (J. E. Maddux Ed), Self-efficacy, adaptation, and adjustment: Theory, research, and application (p. 109-142). New York: Plenum.

Dubreuil, P., Forest, J. ve Courcy, F. (2014). From strengths use to work performance: The role of harmonious passion, subjective vitality, and concentration. The Journal of Positive Psychology, 9(4), 335-349. DOI: 10.1080/17439760.2014.898318

Ekici, G. (2009). Biyoloji öz-yeterlik ölçeğinin Türkçe'ye uyarlanması. Kastamonu Ĕ̆itim Dergisi,17(1), 111-124.

Gangloff, B. ve Mazilescu, C-A. (2017). Normative characteristics of perceived self-efficacy. Social Sciences, MDPI, Open Access Journal, 6(4), 1-18. DOI: $10.3390 /$ socsci6040139.

Guadagnoli, E. ve Velicer, W. F. (1988). Relation to sample size to the stability of component patterns. Psychological Bulletin, 103(2), 265-275. DOI: 10.1037/0033-2909.103.2.265

Hodges, T. D. ve Clifton, D. O. (2004). Strengths-based development in practice. Positive. Psychology in Practice, 1, 256-268.

Hodges, T. D. ve Asplund, J. (2010). Strengths development in the workplace. In (P. Linley, S. Harrington, and N. Garcea Eds.), Oxford handbook of positive psychology and work (p. 213-220). New York, NY: Oxford University Press.

Jinks, J. ve Morgan, V. (1999). Children's perceived academic self-efficacy: An inventory scale. The Clearing House, 72(4), 224-230. Retrieved from http://www.jstor.org/stable/30189583

Kiremit, H. (2006). Fen bilgisi öğretmenliği öğrencilerinin biyoloji ile ilgili öz- yeterlik inançlarının karşılaştırılması. Yayımlanmamış doktora tezi. Dokuz Eylül Üniversitesi, İzmir. 
Kline, P. (1994). An easy guide to factor analysis. New York: Routledge.

Kline, R. B. (2005). Principles and practice of structural equation modeling (2nd ed.). New York: The Guilford Press.

Korkmaz, İ. (2009). Sosyal öğrenme kuramı. (B. Yeşilyaprak Ed.), Eğitim psikolojisi gelişim-öğrenme öğretim içinde (s.218-238). Ankara: Pegem Akademi.

Kotaman, H. (2008). Özyeterlilik inancı ve öğrenme performansının geliştirilmesine ilişkin yazın taraması. Uludağ Üniversitesi Ĕ̆itim Fakültesi Dergisi, 21(1), 111-133.

Kurbanoğlu, S. S. (2004). Öz-yeterlik inancı ve bilgi profesyonelleri için önemi. Bilgi Dünyası, 5(2), 137-152.

Lane, F. C. ve Chapman, N. H. (2011). The relationship of hope and strength's self-efficacy to the social change model of leadership. Journal of Leadership Education, 10(2), 116-137. DOI: 10.12806/V10/I2/RF6

Linley, P. A., Woolston, L. ve Biswas-Diener, R. (2009). Strengths coaching with leaders. International Coaching Psychology Review, 4(1), 37-48.

Littman-Ovadia, H. ve Steger, M. (2010). Character strengths and well-being among volunteers and employees: Toward an integrative model. The Journal of Positive Psychology, 5, 419-430. DOI:10.1080/17439760.2010.516765

Loehlin, J. C. (2004). Latent Variable models: An introduction to factor, path, and structural equation analysis. New Jersey: Lawrence Erlbaum Associates, Inc.

Lopez, F. G. ve Lent, R. W. (1992). Sources of mathematics self-efficacy in high school students. The Career Development Quarterly, 41(1), 3-12. DOI: 10.1002/j.2161-0045.1992.tb00350.x

Lopez, S. J. ve Louis, M. C. (2009). The principles of strengths-based education. Journal of College and Character, 10(4). DOI: 10.2202/1940-1639.1041

Lorsbach, A. ve Jinks, J. (1999). Self-efficacy theory and learning environment research. Learning Environments Research, 2(2), 157-167. DOI: 10.1023/A:1009902810926

Luszczynska, A., Mohamed, N. E. ve Schwarzer, R. (2005). Self-efficacy and social support predict benefit finding 12 months after cancer surgery: The mediating role of coping strategies. Psychology, Health $\&$ Medicine, 10(4), 365-375. DOI: 10.1080/13548500500093738. 
Luszczynska, A., Scholz, U. ve Schwarzer, R. (2005). The General Self-Efficacy Scale: multicultural validation studies. The Journal of Psychology, 139(5), 439-457. DOI: 10.3200/JRLP.139.5.439-457

Luthans, F., Youssef, C. M. ve Avolio, B. J. (2006). Psychological capital: developing the human competitive edge. Oxford University Press.

Maddux, J. E. ve Rogers, R. W. (1983). Protection motivation and self-efficacy: A revised theory of fear appeals and attitude change. Journal of Experimental Social Psychology, 19(5), 469-479. DOI: 10.1016/00221031(83)90023-9

Mert, A., Duman, A. E. ve Kahraman, M. (2019) ortaöğretim öğrencilerinde kariyer karar verme öz-yeterliğinin yordayıcıları olarak benlik saygısı ve algılanan sosyal destek. YYÜ Eğitim Fakültesi Dergisi (YYU Journal of Education Faculty), 16(1), 594-619. DOI: 10.23891/efdyyu.2019.137.

Pajares, F. (1996). Self-efficacy beliefs in academic settings. Review of Educational Research, 66(4), 543-578. DOI: 10.3102/00346543066004543

Pajares, F., Johnson, M. J. ve Usher, E. L. (2007). Sources of writing self-efficacy beliefs of elementary, middle, and high school students. Research in the Teaching of English, 42(1), 104-120. Retrieved from http://www.jstor.org/stable/40171749

Peterson, C., Ruch, W., Beermann, U., Park, N. ve Seligman, M. P. (2007). Strengths of character, orientations to happiness, and life satisfaction. The Journal of Positive Psychology, 2, 149-156. DOI:10.1080/1743976070122893

Ramos-Sánchez, L. ve Nichols, L. (2007). Self-efficacy of first-generation and non-firstgeneration college students: The relationship with academic performance and college adjustment. Journal of College Counselling, 10(1), 6-18. DOI:10.1002/j.2161- 1882.2007.tb00002.x

Sakız, H., Ekinci, N. ve Sarıçam, H. (2019). Teachers' perceptions of their school managers' skills and their own self-efficacy levels. International Journal of Leadership in Education. Advance online Publication. DOI: 10.1080/13603124.2018.1562094

Sarıçam, H. (2015). Mediating role of self-efficacy on the relationship between subjective vitality and school burnout in Turkish adolescents. International Journal of Educational Researchers, 6(1), 1-12. 
Sarıçam, H. ve Adam Karduz, F. F. (2018). Sosyal medya kullanım bozukluğu ölçeğinin Türk kültürüne uyarlanması: Geçerlik ve güvenirlik çalışması. Eğitimde ve Psikolojide Ölçme ve Değerlendirme Dergisi, 9(2), 116135. DOI:10.21031/epod.335607

Saricam, H. ve Canatan, A. (2015). The adaptation, validation, reliability process of the Turkish version Orientations to Happiness Scale. Üniversitepark Bülten, 4(1-2), 7-15. DOI: 10.12973/unibulletin.412.1

Sarıçam, H. ve Sakız, H. (2014). Burnout and teacher self-efficacy among teachers working in special education institutions in Turkey. Educational Studies, 40(4), 423-437. DOI: 10.1080/03055698.2014.930340

Sarıçam, H., Çelik, İ. ve Oğuz, A. (2016). Kısa azim (sebat) ölçeğinin Türkçeye uyarlanması: Geçerlik ve güvenirlik çalışması. Uluslararası Türkçe Edebiyat Kültür Eğitim Dergisi, 5(2), 927-935. DOI: 10.7884/teke.622

Sarıçam, H., Ilbay, A. B., Uysal, R., Çardak, M. ve Akın, A. (2012, May). Turkish version of the short form of resilience appraisal scale: the validity and reliability study. Paper presented at the International Counseling and Education Conference 2012 (ICEC 2012), Istanbul, Turkey. DOI: 10.13140/RG.2.1.4252.1201.

Schunk, D. H. (1991). Self-efficacy and academic motivation. Educational Psychologist, 26(3-4), 207-231. DOI: 10.1207/s15326985ep2603\&4 2

Schunk, D. H. ve Pajares, F. (2010). Self-efficacy beliefs. In (S. Järvelä Ed.) Social and Emotional Aspects of Learning (p. 668-672). Oxford: Elsevier Academic Press.

Senemoğlu, N. (2009). Gelişim öğrenme ve öğretim: kuramdan uygulamaya. (Geliştirilmiş 15.Baskı.) . Ankara: PegemA Yayıncılık.

Snyder, C. R., Shorey, H. S., Cheavens, J., Pulvers, K. M., Adams III, V. H. ve Wiklund, C. (2002). Hope and academic success in college. Journal of Educational Psychology, 94(4), 820.

Stajkovic, A. D., Luthans, F. (1998a). Social cognitive theory and self-efficacy: Going beyond traditional motivational and behavioral approaches. Organizational Dynamics, 26, 62-74.

Stajkovic, A. D. ve Luthans, F. (1998b). Self-efficacy and work-related performance: A meta-analysis. Psychological Bulletin, 124, 240-261. DOI:10.1037/0033-2909.124.2.240. 
Tsai, C. L., Chaichanasakul, A., Zhao, R., Flores, L. Y. ve Lopez, S. (2014). Development and validation of the Strengths Self-Efficacy Scale (SSES). Journal of Career Assessment, 22(2), 221-232. DOI: 10.1177/1069072713493761.

Tiyuri, A., Saberi, B., Miri, M., Shahrestanaki, E., Bayat, B. B. ve Salehiniya, H. (2018). Research self-efficacy and its relationship with academic performance in postgraduate students of Tehran University of Medical Sciences in 2016. Journal of Education and Health Promotion, 7, 11. DOI:10.4103/jehp.jehp_43_17

Uysal, İ. (2013). Akademisyenlerin genel öz-yeterlik inançları: AİBÜ Eğitim Fakültesi örneği. Trakya Üniversitesi Ĕ̆itim Fakültesi Dergisi, 3(2).

Verroen, S., Gutteling, J. M. ve De Vries, P. W. (2013). Enhancing self-protective behavior: Efficacy beliefs and peer feedback in risk communication. Risk Analysis, 33(7), 1252-1264. DOI: 10.1111/j.15396924.2012.01924.x

Wood, R. ve Bandura, A. (1989). Impact of conceptions of ability on self-regulatory mechanisms and complex decision making. Journal of Personality and Social Psychology, 56(3), 407-415. DOI: 10.1037/0022$\underline{3514.56 .3 .407}$

Yıldırım, F. ve İlhan, İ. Ö. (2010). Genel Öz-Yeterlilik Ölçeği Türkçe formunun geçerlilik ve güvenilirlik çalışması. Türk Psikiyatri Dergisi, 21(4), 301308.

Yılmaz, M., Gürçay, D. ve Ekici, G. (2007). Akademik özyeterlik ölçeğinin Türkçe'ye uyarlanması. Hacettepe Üniversitesi Eğitim Fakültesi Dergisi, 33, 253-259.

Zimmerman, B. J. (1995). Self-efficacy and educational development. In (A. Bandura Ed). Self efficacy in changing societies. New York: Cambridge University Press.

\section{Kaynakça Bilgisi / Citation Information}

Sarıçam, H., Mert, A. ve Çelik, İ. (2019). Güçlü yönler öz-yeterlik ölçeğinin Türkçe versiyonunun psikometrik özellikleri. OPUS-Uluslararası Toplum Araştırmaları Dergisi , 14(20), 288-313. DOI: 10.26466/opus.587269 